TITLE:

\title{
Smoke Reduction Effects by Post Injection for Various Injection Parameters and Combustion Chamber Shapes in a Diesel Engine
}

\section{$\operatorname{AUTHOR}(\mathrm{S})$ :}

Horibe, Naoto; Komizo, Tatsuya; Sumimoto, Takashi; Wang, Hao; Ishiyama, Takuji

\section{CITATION:}

Horibe, Naoto ...[et al]. Smoke Reduction Effects by Post Injection for Various Injection Parameters and Combustion Chamber Shapes in a Diesel Engine. SAE Technical Papers 2014: 2014-01-2634.

\section{ISSUE DATE:}

2014-10-13

URL:

http://hdl.handle.net/2433/237658

\section{RIGHT:}

This is the accepted manuscript of the article, which has been published in final form at https://doi.org/10.4271/2014 01-2634:; The full-text file will be made open to the public on 13 April 2015 in accordance with publisher's 'Terms and Conditions for Self-Archiving'; この論文は出版社版でありません。引用の際には出版社版をご確認ご利用ください。; This is not the published version. Please cite only the published version. 


\title{
Smoke Reduction Effects by Post Injection for Various Injection Parameters and Combustion Chamber Shapes in a Diesel Engine
}

\author{
Naoto Horibe, Tatsuya Komizo, Takashi Sumimoto, Hao Wang and Takuji Ishiyama \\ Kyoto University
}

Copyright @ 2014 SAE International

\begin{abstract}
A series of experiments using a single-cylinder direct injection diesel engine was conducted to investigate the smoke reduction effect of post injection while varying numerous parameters: the post-injection quantity, post-injection timing, injection pressure, main-injection timing, intake pressure, number of injection nozzle orifices, and combustion chamber shape. The experiments were performed under a fixed NOx emission condition by selecting the total injection quantities needed to obtain the predetermined smoke emission levels without post injection. The smoke reduction effects were compared when changing the post injection timing for different settings of the above parameters, and explanations were found for the measured smoke emission trends. The results indicate that close post injection provides lower smoke emission for a combination of a reentrant combustion chamber and sevenhole nozzle. The same trend was also found in the tests that varied the injection pressure, main-injection timing, and intake pressure. However, a lower sensitivity of the smoke emission to the post injection timing was observed when using an injection nozzle with a larger number of orifices and a toroidal combustion chamber. The smoke reduction rate at the best post injection timing was higher for a lower injection pressure, larger number of nozzle orifices, and toroidal combustion chamber. The reasons for these trends were investigated, giving attention to the relation between the main spray flames and post sprays.
\end{abstract}

\section{Introduction}

Automotive diesel engines are often equipped with commonrail fuel injection systems, and multistage injection strategies have played a significant role in combustion control to satisfy the stringent emission regulations with higher thermal efficiency and lower combustion noise. Post injection, in which a small amount of fuel is injected after the end of the main injection, has been proved to have a smoke-reduction effect when the post injection conditions were optimized. However, no smoke reduction effects are obtained, and negative effects are also observed when the post injection timing and quantity deviate from the proper settings for each engine operating condition. Many researchers have investigated the effect of post injection [1-13]. Ikemoto et al. showed that close post injection reduces smoke emission [10], whereas Desantes et al., in contrast, showed that retarded post injection reduces smoke emission [7]. The smoke reduction effect of post Page 1 of 11 injection against the post injection timing seems to depend on the operating conditions and specifications of the engine.

Ikemoto suggested a smoke reduction mechanism for post injection based on the results of experiments using an optical engine with a small bore: the main spray flame impinges on the side wall of the piston bowl and bounds back. Then, it flows along the bottom of the piston bowl to the center region of the combustion chamber. As time passes, the tip of the main spray flame rolls up and blocks the path of the post spray. When applying early post injection, the post spray is able to entrain sufficient oxygen before the main spray flame reaches the path, as shown in Fig. 1(a). In this case, soot from the main spray decreases because a portion of the main injection fuel is moved to the post injection and, in addition, soot from the post injection is suppressed. Therefore, close post injection leads to low smoke emission. On the other hand, retarded post injection entrains a high-temperature and low-oxygen mixture from the main spray flame, which rolls up to interrupt the post spray (Fig. 1(b)). Therefore, soot from the post injection increases, which leads to a smaller smoke reduction effect from the post injection.

Desantes performed experiments using a small-bore engine and pilot-main-post three-stage injection, and reported that the smoke emissions had little dependence on the post injection timing in the case of a small amount of post injection. The smoke level was always close to that in the case of a reduced main injection without post injection, in which the total injection mass was reduced by the removal of the post injection. The phenomena were explained by the separate combustions of the main and post sprays, or "split flame." On the other hand, in the case of a large amount of post injection, a close post injection increased the smoke emission compared with the case without post injection. However, retarding the post injection provided a lower smoke emission, and the smoke level approached that of the reduced main injection without post injection. In this case, the reason for the smoke trend was also explained by the "split flame." 


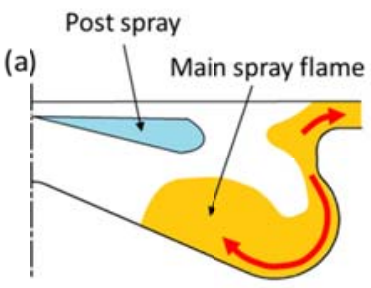

(b)

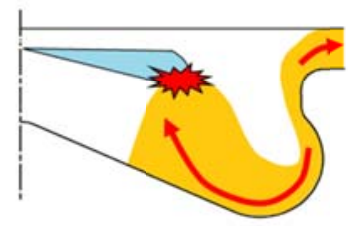

Figure 1. Interaction images of main spray flame and post spray: (a) advanced post injection and (b) retarded post injection.

These studies indicated that the interaction between the main spray flames and post sprays plays an important role in the smoke reduction effect of post injection. The different trends for the post injection parameters would come from the differences in the conditions that influence the distribution of the fuel-air mixture and flame from the main and post injections, such as nozzle specification and piston shape. It is still necessary to accumulate data to understand the details of the smoke reduction effect and obtain strategies to control the post injection according to the engine operating conditions and specifications.

This study had the goal of quantitatively comparing the smoke reduction effects of post injection when changing the various parameters and deriving qualitative explanations for the trends obtained from the experiments. In our previous study [12], explanations were given for the change in the smoke reduction effect with different parameters by considering the change in the interaction between the main spray flames and post sprays. In this study, the same approach was employed: attention was given to the spread and roll up of the main spray flame and its interference with the post spray, which is illustrated in Fig. 1.

For this purpose, a series of experiments was carried out with pilot-main-post three-stage injection using a single-cylinder diesel engine and changing the post injection timing for different settings of the parameters: the post-injection quantity, injection pressure, boost pressure, main-injection timing, number of injection nozzle orifices, and combustion chamber shape. Data for the performances and exhaust emissions were obtained at a fixed NOx emission level by selecting the total injection quantity so that the smoke emission level without post injection was equal to a predetermined value. Then, the smoke emission trend in relation to the post injection timing was investigated for each parameter. The smoke reduction rates in the tests with different parameters were defined and compared, and the reasons for the changes in the rate were examined.

\section{Experimental Setup}

An outline of the experimental system used in this study is illustrated in Fig. 2. The test engine was a water-cooled singlecylinder four-stroke-cycle direct-injection diesel engine. The major specifications of the engine are given in Table 1. To regulate the intake charge condition, an external supercharger and intercooler were installed. A low-pressure loop exhaust gas recirculation (EGR) system was employed, including a diesel particulate filter (DPF) to protect the supercharger from the soot contamination.

Page 2 of 11

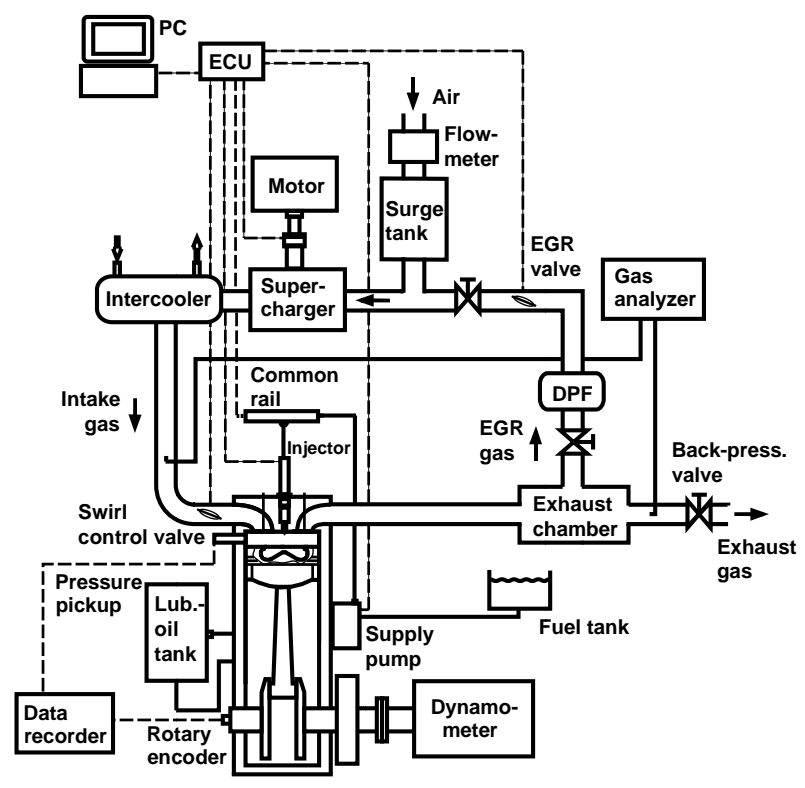

Figure 2. Experimental setup.

Table 1. Major engine specifications.

\begin{tabular}{|l|l|}
\hline Engine type & $\begin{array}{l}\text { Direct-injection, single-cylinder, } \\
\text { water-cooled diesel engine }\end{array}$ \\
\hline Displacement [cc] & 550 \\
\hline Bore [mm] & 85.0 \\
\hline Stroke [mm] & 96.9 \\
\hline Compression ratio [-] & $16.3: 1$ \\
\hline Number of valves [-] & 4 (Intake 2, Exhaust 2) \\
\hline Injection system & $\begin{array}{l}\text { Common-rail system } \\
\text { with solenoid injector } \\
\text { (Max. press.: 180 MPa) }\end{array}$ \\
\hline Supercharging & External supercharging \\
\hline EGR system & Low-pressure loop EGR \\
\hline
\end{tabular}

The experimental conditions are listed in Table 2. All of the experiments were performed under thermally steady states for the engine at a fixed speed of $1,500 \mathrm{rpm}$, an inlet coolant temperature of $80^{\circ} \mathrm{C}$, and a lubricating oil temperature of $80^{\circ} \mathrm{C}$. The fuel was commercial JIS No.2 diesel fuel (density at $15^{\circ} \mathrm{C}$ : $820.7 \mathrm{~kg} / \mathrm{m}^{3}$, cetane index: 55). The fuel injection nozzles had the same hydraulic flow rate $(680 \mathrm{~mL} / \mathrm{min} @ 100 \mathrm{kPa})$ and spray angle $\left(156^{\circ}\right)$. Figure 3 illustrates the shapes of the piston bowl and spray direction at top dead center (TDC). Re55 is a reentrant-type piston, and T55 is a toroidal-type piston. These pistons have equal bowl volumes and almost the same geometries, except for the squish lip. The underlined values in Table 2 are the standard conditions. Based on the previous study [12], the pilot injection quantity was set at $6 \mathrm{~mm}^{3} /$ cycle to realize the entirely mixing-controlled combustion of the main spray and a relatively high smoke level for easy detection of the soot reduction effect of post injection. To compare the smoke reduction effects of post injection under various conditions, the main-injection quantity was adjusted to set the smoke emission level at $1 \mathrm{FSN}$ and $2 \mathrm{FSN}$ when post injection was not used, i.e., for a pilot-main two-stage injection mode. Then, post injection was applied with the same total injection

2 of 11 
quantity. The NOx emissions in all cases were kept at $150 \pm 5$ ppm by adjusting the EGR rate for each smoke level to eliminate the difference in the NOx emissions caused by the change in the post injection conditions. The post-injection timing was varied from the most advanced timing to $21^{\circ}$ ATDC, where the post-injection quantity was kept constant by adjusting the duration of the post injection signal. The most advanced timings were selected to prevent the unstable injection caused by the limitation of the injector response. The exhaust back pressure valve was fully open. The parameters that were changed in the experiments included the postinjection quantity, injection pressure, boost pressure, maininjection timing, injection nozzle specification, and combustion chamber shape. When one of the parameters was varied, the other parameters were kept at the standard conditions.

Table 2. Engine operating conditions.

\begin{tabular}{|c|c|}
\hline Engine speed [rpm] & 1500 \\
\hline Fuel & JIS No.2 diesel fuel \\
\hline Nozzle hole dia. $[\mathrm{mm}] \times$ num. $[-]$ & $\phi 0.125 \times 7, \phi 0.105 \times 10$ \\
\hline Combustion chamber shape & $\frac{\text { Reentrant (Re55), }}{\text { Toroidal (T55) }}$ \\
\hline Injection pressure [MPa] & $70, \underline{90}, 125$ \\
\hline Boost pressure [kPa (abs.)] & $\underline{120}, 140$ \\
\hline Intake temperature $\left[{ }^{\circ} \mathrm{C}\right]$ & $\underline{35}$ \\
\hline Pilot-inj. quantity [ $\mathrm{mm}^{3} /$ cycle] & $\underline{6}$ \\
\hline Pilot-inj. timing $\left[{ }^{\circ} \mathrm{ATDC}\right]$ & -19 \\
\hline Main-inj. quantity & $\begin{array}{l}\text { Adjusted for smoke } \\
\approx 1 \mathrm{FSN} \text { or } 2 \mathrm{FSN}\end{array}$ \\
\hline Main-inj. timing $\left[{ }^{\circ}\right.$ ATDC] & $-1, \underline{1}, 3$ \\
\hline Post-inj. quantity [ $\mathrm{mm}^{3} /$ cycle] & $2, \underline{4}, 6$ \\
\hline Post-inj. timing [ $\left.{ }^{\circ} \mathrm{ATDC}\right]$ & $\sim 21$ \\
\hline Swirl ratio [-] & 1.8 \\
\hline NOx emission [ppm] & $\underline{150 \pm 5}$ \\
\hline
\end{tabular}
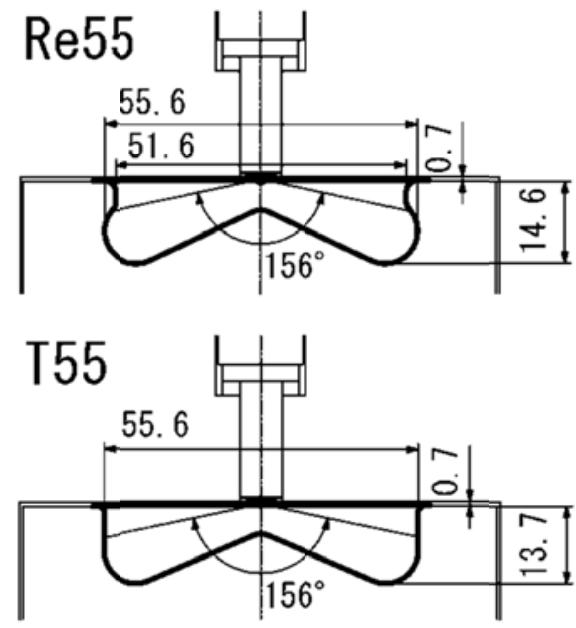

Figure 3. Combustion chamber geometry and spray direction.

The in-cylinder pressure was measured using a piezoelectric pressure transducer (Kistler $6052 \mathrm{~A}$ ). The average pressure for Page 3 of 11
50 cycles was used to calculate the heat release rate. A filtertype smoke meter (AVL 415S) was used for the smoke emission, and a heated flame ionization detector and total hydrocarbon (THC) analyzer (Horiba MEXA-1170HFID) was used to measure the hydrocarbon concentration. A chemiluminescent analyzer (Thermo Fisher Scientific Model 42i-HL) was used for the NOx concentration, and a nondispersive infrared analyzer (Round Science ALTAS12) was used to measure the $\mathrm{CO}$ and $\mathrm{CO}_{2}$ concentrations. Finally, a paramagnetic oxygen analyzer (Round Science RSOM-2510) was used to measure the oxygen concentration.

The injection durations and delay times from the injection command to the actual injection start were obtained from the experiments using a Bosch-type injection rate meter under the same injection pressures, injection command dwells, and injection command durations as those applied in the engine experiments. Based on the results, the actual injection timings and durations are displayed in the graphs.

\section{Selection of Main-Injection Quantity}

First, experiments with two-stage (pilot + main) injection were conducted by varying the main-injection quantity, in which the NOx concentration was kept at $150 \mathrm{ppm}$ by adjusting the EGR rate. Based on the results, the total injection quantities for smoke emission levels of approximately 1 FSN and 2 FSN were recorded, and then the smoke-reduction effects of post injection were investigated at the total injection quantities obtained. For example, the case of changing the injection pressure is illustrated in Fig. 4, which shows the smoke emission against the total injection quantity $q_{\mathrm{f}}$ for injection pressures $p_{\mathrm{j}}$ of 70,90 , and $125 \mathrm{MPa}$. Here, $q_{\mathrm{f}}=25,29$, and 31 $\mathrm{mm}^{3} /$ cycle were chosen for $p_{\mathrm{j}}=70,90$, and $125 \mathrm{MPa}$, respectively, for $1 \mathrm{FSN}$ (low smoke). Similarly, $q_{\mathrm{f}}=31,33$, and $34 \mathrm{~mm}^{3} /$ cycle were chosen for $p_{\mathrm{j}}=70,90$, and $125 \mathrm{MPa}$, respectively, for 2 FSN (high smoke).

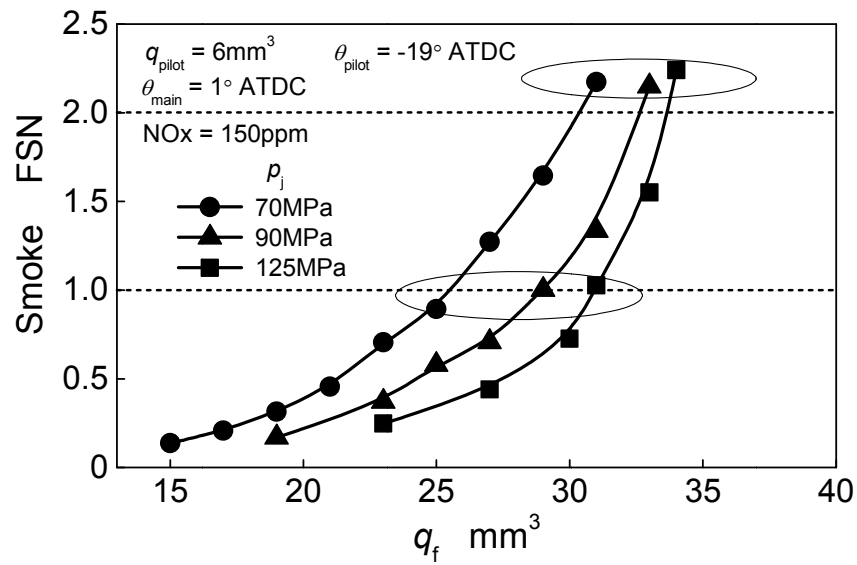

Figure 4. Smoke emission against total injection quantity for pilot-main two-stage injection when varying injection pressure.

\section{Results and Discussions}

\section{Effect of Post-Injection Quantity}

The effect of the post-injection quantity was investigated. The total injection quantities were $29 \mathrm{~mm}^{3} /$ cycle for low-smoke 
cases and $33 \mathrm{~mm}^{3} /$ cycle for high-smoke cases. The postinjection quantity $q_{\text {post }}$ was set at 2,4 , and $6 \mathrm{~mm}^{3} /$ cycle.

Figure 5 shows the smoke, $\mathrm{CO}, \mathrm{THC}$, intake $\mathrm{O}_{2}$, indicated thermal efficiency, and indicated mean effective pressure (IMEP) against the post-injection timing for the low- and highsmoke cases. The results of two cases without post injection (pilot + main) and (pilot + reduced main) are also shown. Reduced main injection means that the total injection mass was reduced by the removal of the post injection. To maintain the NOx concentration, the EGR rate was increased as the post injection was advanced because the heat release from the post spray was advanced, and therefore the in-cylinder temperature around the TDC increased. This reduced the intake $\mathrm{O}_{2}$ concentration. Nevertheless, the smoke emission decreased with the advance in the post injection. The reason for this phenomenon was already explained in the Introduction.

The smoke emission for the largest post injection quantity case $q_{\text {post }}=6 \mathrm{~mm}^{3} /$ cycle, was higher than that without post injection at post injection timings later than $14^{\circ} \mathrm{ATDC}$ for the high-smoke case and later than $11^{\circ}$ ATDC for the low-smoke case. The spread and roll-up of the main spray flame in Fig. 1 would be suppressed in this case. However, the post spray region was rapidly expanded by the large quantity of post injection, which led to a stronger interaction between the main spray flame and post spray. On the other hand, for the most advanced post injection, the smoke emission was not significantly higher than in the other post injection quantity cases. The $\mathrm{CO}$ and THC emissions were less affected by the post injection conditions. The IMEP and indicated thermal efficiency were almost the same or superior for the close post injection compared to those without post injection. However, they decreased as the post injection timing was retarded because of the lower degree of constant volume. The post injection timing only slightly affected the exhaust temperature because the range of the timing was not very wide: the rise in the exhaust temperature by post injection was within $5 \mathrm{~K}$ compared to the case without post injection, which means that the influence on the aftertreatment will be small.
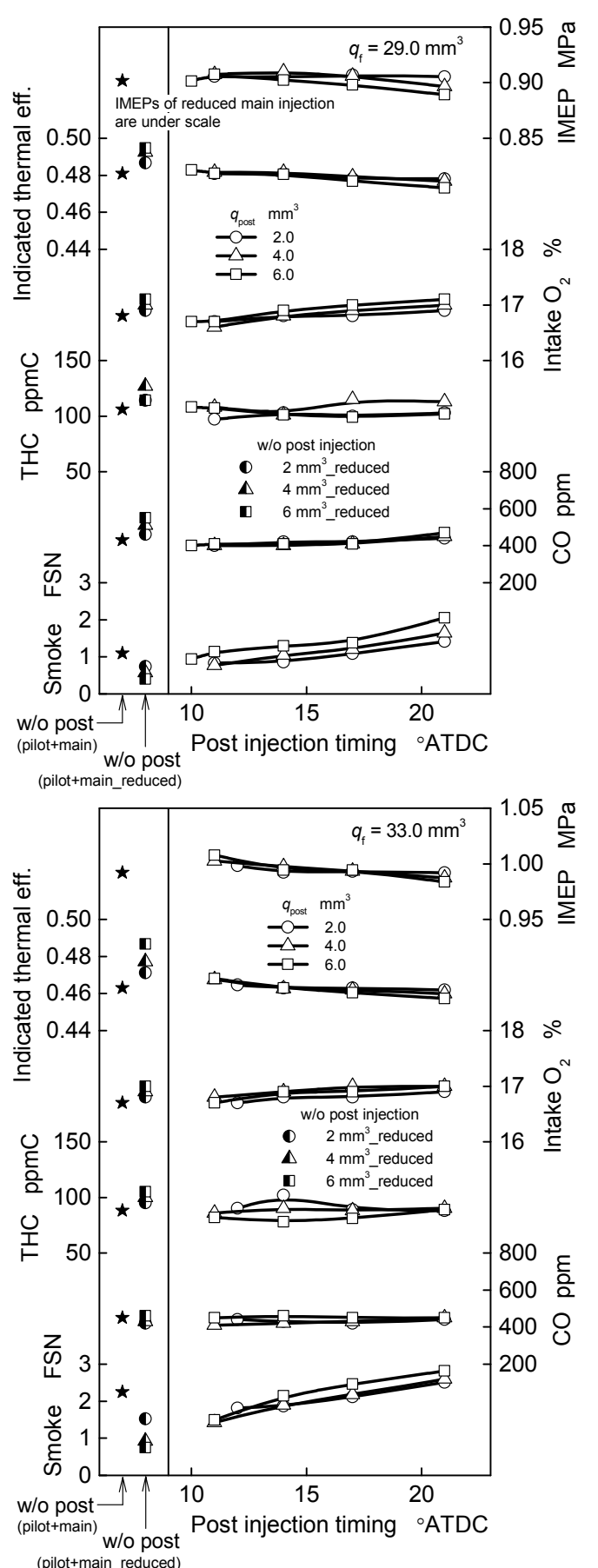

Figure 5. Effects of post injection quantity on performance and emissions (upper: low smoke, lower: high smoke).

\section{Effect of Injection Pressure}

The effect of the injection pressure $p_{\mathrm{j}}$ was investigated, with $p_{\mathrm{j}}$ set at 70,90 , and $125 \mathrm{MPa}$. The total injection quantities for each injection pressure are listed in Table 3.

Table 3. Total injection quantities for various injection pressures. 


\begin{tabular}{|l|c|c|c|}
\hline $\begin{array}{l}\text { Low } \\
\text { Smoke }\end{array}$ & $25.0 \mathrm{~mm}^{3} /$ cycle & $29.0 \mathrm{~mm}^{3} /$ cycle & $31.0 \mathrm{~mm}^{3} /$ cycle \\
\hline $\begin{array}{l}\text { High } \\
\text { Smoke }\end{array}$ & $31.0 \mathrm{~mm}^{3} /$ cycle & $33.0 \mathrm{~mm}^{3} /$ cycle & $34.0 \mathrm{~mm}^{3} /$ cycle \\
\hline
\end{tabular}

Figure 6 shows the effects of the injection pressure on the performance and emissions. The $\mathrm{CO}$ and THC data are not shown in this figure because they were only slightly influenced by the post injection conditions. Increasing the injection pressure reduced the smoke reduction effect, which means the smoke difference between the most advanced post injection case and the two-stage injection case without post injection. Under late post injection conditions, higher injection pressures (90 and $125 \mathrm{MPa}$ ) increased the smoke emission compared with the two-stage injection case. This effect was remarkable in the low-smoke case. Increasing the injection pressure enhanced the penetrations of both the main and post sprays, and led to a strong interaction between them. A decrease in the smoke emission with the advance of the post injection was observed in every injection pressure case. However, the change in the smoke emission with the post injection timing was very small in the low-smoke case with the lowest injection pressure. This was probably because there was a weak interaction between the main spray flame and post spray regardless of the post injection timing, caused by the small main injection quantity and low penetration of the post spray.
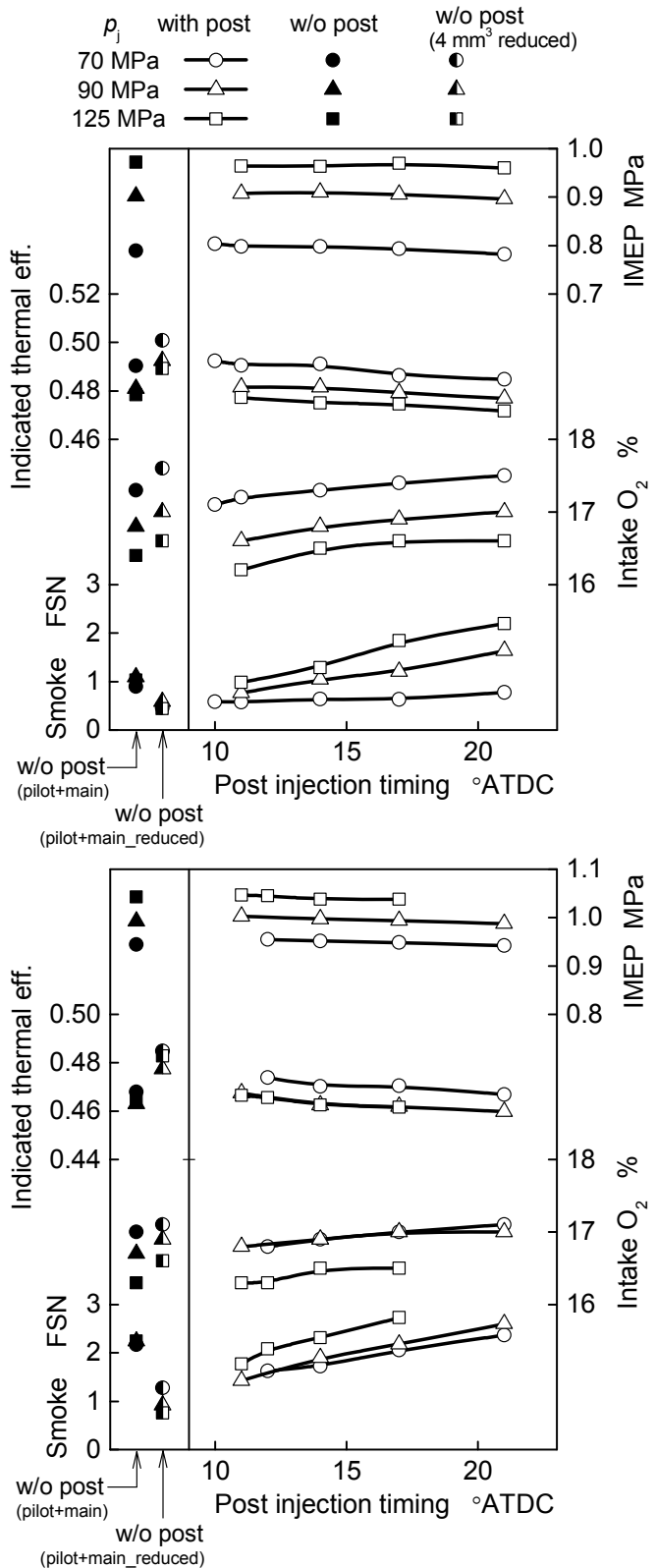

Figure 6. Effects of injection pressure on performance and emissions (upper: low smoke, lower: high smoke).

\section{Effect of Boost Pressure}

The boost pressure $p_{\mathrm{b}}$ was varied from 120 to $140 \mathrm{kPa}$ (abs.). The increase in $p_{\mathrm{b}}$ from 120 to $140 \mathrm{kPa}$ reduced the smoke emission without post injection from 2 to 1 FSN. The total injection quantities are listed in Table 4.

Table 4. Total injection quantities for standard and higher boost pressures.

\begin{tabular}{|l|l|c|}
\cline { 2 - 3 } \multicolumn{1}{c|}{} & $p_{\mathrm{b}}=120 \mathrm{kPa}$ & $140 \mathrm{kPa}$ \\
\hline $\begin{array}{l}\text { Low } \\
\text { Smoke }\end{array}$ & $29.0 \mathrm{~mm}^{3} /$ cycle & $34.0 \mathrm{~mm}^{3} /$ cycle \\
\hline $\begin{array}{l}\text { High } \\
\text { Smoke }\end{array}$ & $33.0 \mathrm{~mm}^{3} /$ cycle & $38.0 \mathrm{~mm}^{3} /$ cycle \\
\hline
\end{tabular}


Table 5. Total injection quantities for each main-injection timing.

The results are shown in Fig. 7. In addition, in the case with a higher boost pressure, a tendency for the smoke to decrease with the advance of the post injection appeared, and the boost pressure hardly affected the smoke emission at the most advanced post injection. The suppression of the spread of the main spray flame by a higher in-cylinder density and the enhancement of the interaction by an increase in the main injection quantity would cancel each other out.
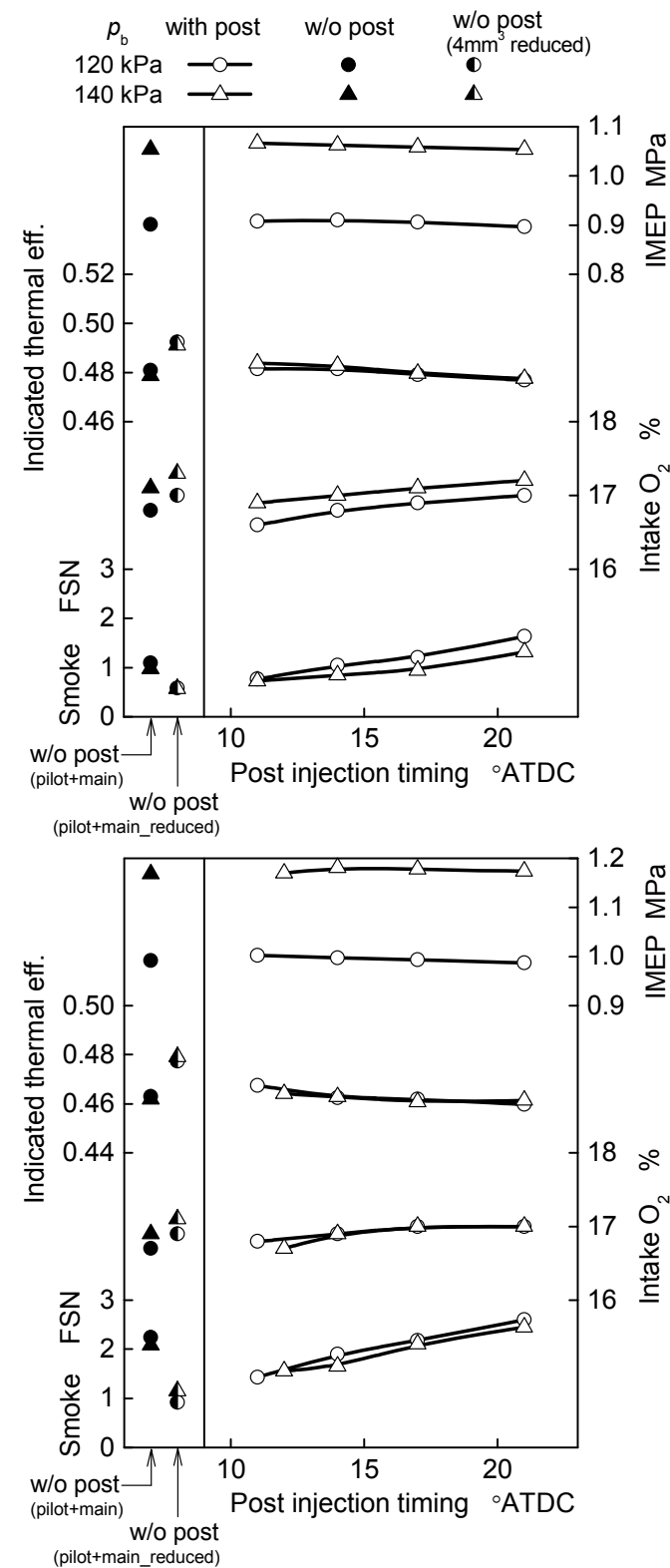

Figure 7. Effects of boost pressure on performance and emissions (upper: low smoke, lower: high smoke).

\section{Effect of Main-Injection Timing}

The main-injection timing $\theta_{\text {main }}$ was varied in the range of $-1^{\circ}$ to $3^{\circ}$ ATDC. The total injection quantities are listed in Table 5.

\begin{tabular}{|l|c|c|c|}
\cline { 2 - 4 } \multicolumn{1}{c|}{} & $\theta_{\text {main }}=-1^{\circ}$ ATDC & $1^{\circ}$ ATDC & $3^{\circ}$ ATDC \\
\hline $\begin{array}{l}\text { Low } \\
\text { Smoke }\end{array}$ & $27.0 \mathrm{~mm}^{3} /$ cycle & $29.0 \mathrm{~mm}^{3} /$ cycle & $28.5 \mathrm{~mm}^{3} /$ cycle \\
\hline $\begin{array}{l}\text { High } \\
\text { Smoke }\end{array}$ & $32.0 \mathrm{~mm}^{3} /$ cycle & $33.0 \mathrm{~mm}^{3} /$ cycle & $33.0 \mathrm{~mm}^{3} /$ cycle \\
\hline
\end{tabular}

The results are shown in Fig. 8. The smoke emission decreased with an advance in the post injection regardless of the main injection timing. At the same post injection timing, the retarded main injection provided a reduced smoke emission. This included the effect of the shorter interval between the main and post injections when retarding the main injection, which would avoid the strong interaction. Figure 9 shows a compilation of the smoke emissions against the interval between the start of the main injection and the start of the post injection. In both the high- and low-smoke cases, the smoke value is almost decided by the interval, irrespective of the main injection timing. 


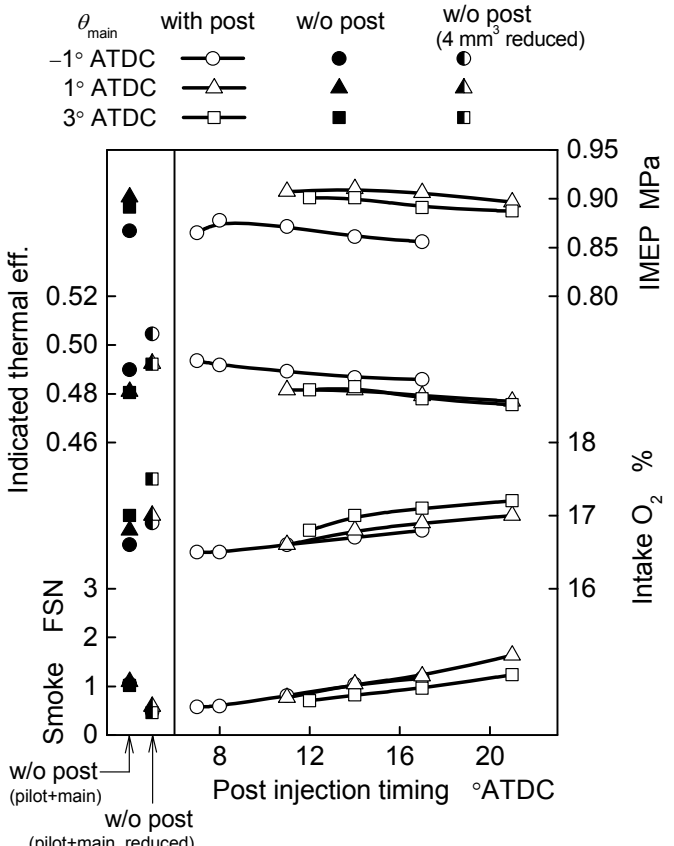

(pilot+main reduced)

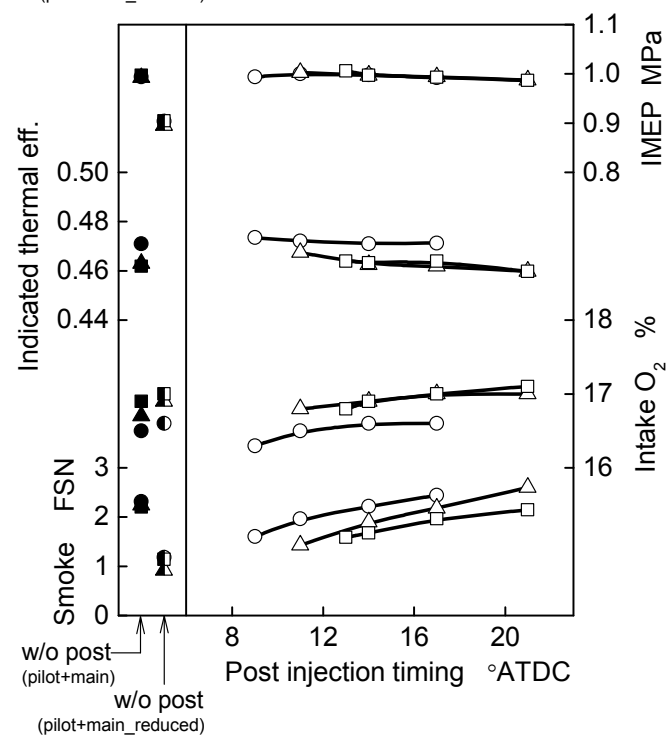

Figure 8. Effects of main-injection timing on performance and emissions (upper: low smoke, lower: high smoke). $\theta_{\text {main }} \quad$ with post w/o post w/o post
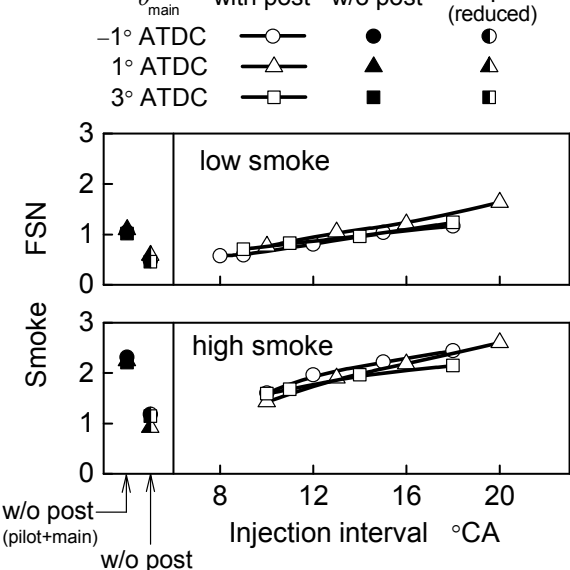

Figure 9. Effect of injection interval on smoke emission.

\section{Effect of Nozzle Specification}

A comparison was made of nozzles with 7 and 10 holes and the same flow rate. The orifice diameters were $0.125 \mathrm{~mm}$ for the 7-hole nozzle and $0.105 \mathrm{~mm}$ for the 10 -hole nozzle. The total injection quantities are listed in Table 6.

Table 6. Total injection quantities for injection nozzles with 7 and 10 holes.

\begin{tabular}{|l|c|c|}
\cline { 2 - 3 } \multicolumn{1}{c|}{} & 7-hole nozzle & 10-hole nozzle \\
\hline $\begin{array}{l}\text { Low } \\
\text { Smoke }\end{array}$ & $29.0 \mathrm{~mm}^{3} /$ cycle & $28.0 \mathrm{~mm}^{3} /$ cycle \\
\hline $\begin{array}{l}\text { High } \\
\text { Smoke }\end{array}$ & $33.0 \mathrm{~mm}^{3} /$ cycle & $32.0 \mathrm{~mm}^{3} /$ cycle \\
\hline
\end{tabular}

The results are shown in Fig. 10. The 10-hole nozzle provided a different smoke emission tendency against the post injection timing. Retarding the post injection initially reduced the smoke emission, whereas further retarding it to $21^{\circ} \mathrm{ATDC}$ increased the smoke emission again. Compared with the 7-hole nozzle, the smoke emission was less sensitive to the post injection timing, especially in the low-smoke case. Figure 11 shows the heat release rates for post injection timing $\theta_{\text {post }}$ values of 11 and $17^{\circ} \mathrm{ATDC}$. The injection duration for the 10 -hole nozzle was slightly longer than that for the 7-hole nozzle as a result of adjusting the injection quantity. The peaks of the heat release rate by post injection were not very different for the two nozzles at $\theta_{\text {post }}=11^{\circ} \mathrm{ATDC}$. On the other hand, at the later post injection timing of $17^{\circ} A T D C$, the heat release rate peak by post injection with the 10-hole nozzle was higher than that with the 7 -hole nozzle. As a result of the shorter spray penetration by the smaller orifices of the 10-hole nozzle, close post injection may have caused interaction between the main spray tail and the post spray. Retarding the post injection would have weakened such interaction. In addition, the spread of the main spray flame was slower because of the shorter penetration of the main spray, which would suppress the main spray flame's interference with the post spray. Further retarding the post injection would increase the interaction because the main spray flame would enter the path of the post spray. However, the interaction for the 10-hole nozzle seemed to be weak 
because of the short penetrations of both the main and post sprays, which resulted in the weak influence of the post injection timing on the smoke emission.
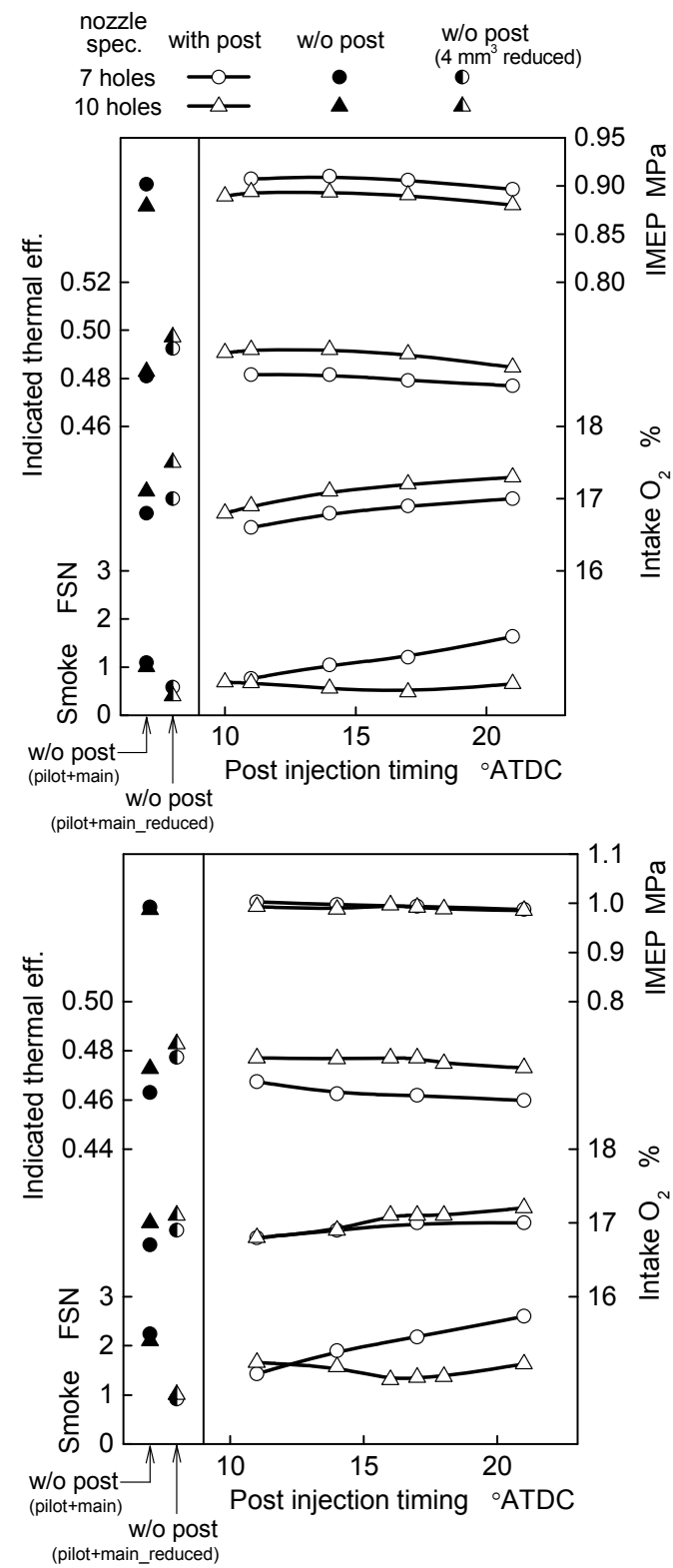

Figure 10. Effects of nozzle specification on performance and emissions (upper: low smoke, lower: high smoke).

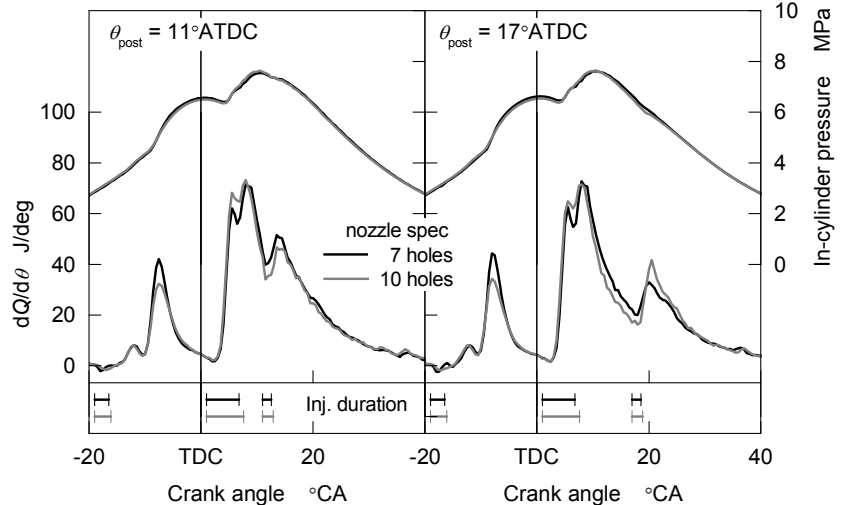

Figure 11. Heat release rates of 7-hole nozzle and 10-hole nozzle at $\theta_{\text {post }}=11$ and $17^{\circ}$ ATDC under low-smoke condition

\section{Effect of Combustion Chamber Shape}

A toroidal combustion chamber T55 was compared with Re55, the standard reentrant combustion chamber. The total injection quantities are listed in Table 7.

Table 7. Total injection quantities for two combustion chambers.

\begin{tabular}{|l|c|c|}
\cline { 2 - 3 } \multicolumn{1}{c|}{} & $\operatorname{Re} 55$ & T55 \\
\hline $\begin{array}{l}\text { Low } \\
\text { Smoke }\end{array}$ & $29.0 \mathrm{~mm}^{3} /$ cycle & $25.0 \mathrm{~mm}^{3} /$ cycle \\
\hline $\begin{array}{l}\text { High } \\
\text { Smoke }\end{array}$ & $33.0 \mathrm{~mm}^{3} /$ cycle & $29.0 \mathrm{~mm}^{3} /$ cycle \\
\hline
\end{tabular}

The results are shown in Fig. 12. In contrast to the standard case (Re55), the post injection timing did not have much influence on the smoke emission for the toroidal combustion chamber (T55). T55 exhibited a smoke emission tendency that was similar to that mentioned above for the 10-hole nozzle. The injection quantity for T55 was less than that for Re55, and T55 did not have the squish lip, which allowed part of the mixture from the main spray to flow into the squish area. Therefore, the fuel mass contained in the piston bowl was smaller for T55. This caused a slower development of the main spray flame, as in the 10-hole nozzle. 

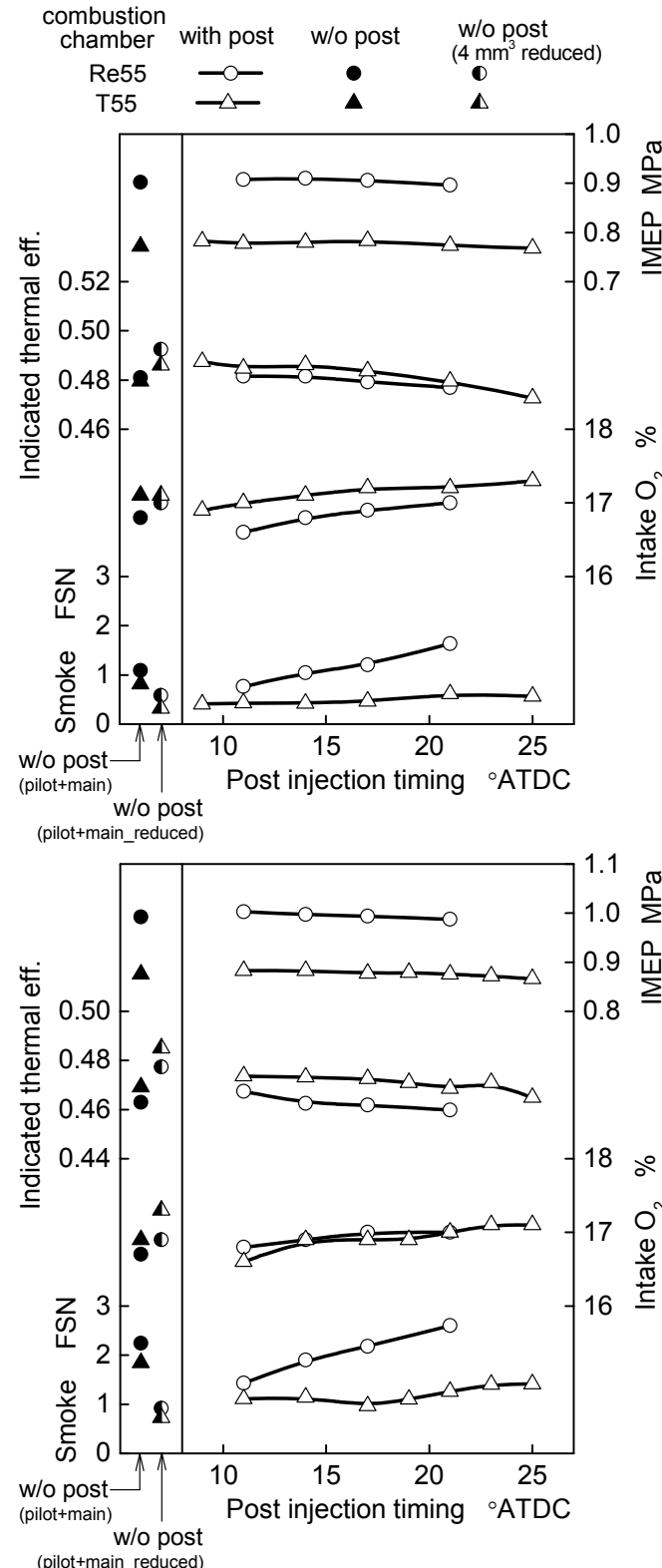

Figure 12. Effects of combustion chamber shape on performance and emissions (upper: low smoke, lower: high smoke).

\section{Comparison of Amounts of Smoke Reduction by Post Injection for Various Conditions}

In order to compare the smoke reduction effects by post injection with different parameters, the smoke reduction rate $\alpha$ is defined as $\alpha=\Delta S / \Delta S_{0}$, which is illustrated in Fig. 13. Here, $\Delta S$ is the smoke-emission difference between the case of twostage injection without post injection (pilot + main, "A" in Fig. 13 ) and the case with post-injection (pilot + main + post, "B"). These cases have the same total injection quantity. $\Delta S_{0}$ is the difference between the case of two-stage injection (pilot + main, "A") and the case of two-stage injection with a reduced main injection (pilot + reduced main, "C"). $\Delta S$ indicates the reduction in smoke emission when post injection is employed instead of increasing the quantity of the main injection. $\Delta S_{0}$ is a reference, and represents the reduction in the smoke emission when a

Page 9 of 11 fuel quantity corresponding to the post injection is removed from the main injection in two-stage injection mode "A." A negative $\alpha$ indicates that the addition of post injection causes a large increase in smoke emission by increasing the soot from the main spray combustion (promoting soot generation and/or interrupting the soot oxidation) and/or increasing the soot from the post spray combustion. If $\alpha$ exceeds unity, this indicates that the post injection markedly reduces the smoke emission, not only by avoiding soot from the post spray but also by significantly reducing the soot from the main spray. In this case, an extra smoke reduction effect is obtained, in addition to the effect by the reduction of the main injection quantity.

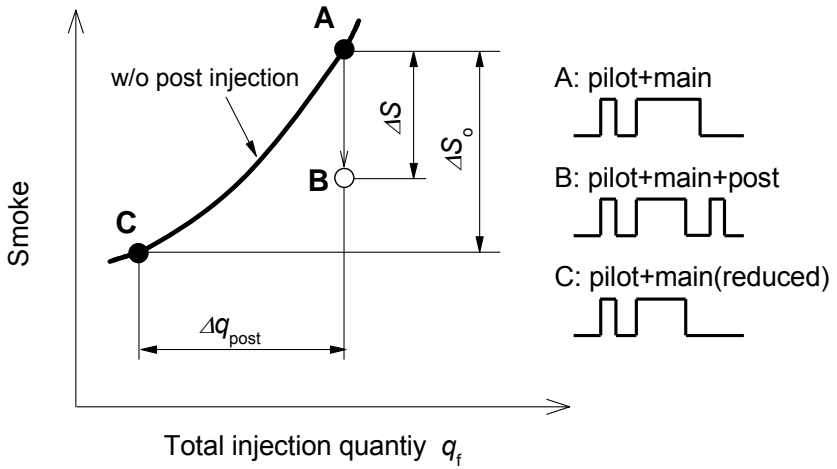

Figure 13. Definitions of $\Delta S$ and $\Delta S_{0}$.

The values of $\alpha, \Delta S, \Delta S_{0}$, and total injection quantity $q_{\mathrm{f}}$ for all the above results are listed in Table 8 . In each parameter test, $\alpha$ was calculated for the selected post injection timing that provided the largest reduction in the smoke emission. $\alpha$ neither fell below zero nor exceeded unity in any case under the experimental conditions in this study: the fixed NOx emission and limited parameter ranges. This means that a smoke reduction effect could certainly be obtained by using post injection if the post-injection timing is properly selected. On the other hand, the above-mentioned extra smoke reduction effect was not observed.

The toroidal combustion chamber (T55) and increased number of nozzle orifices (10 holes) provided a high $\alpha$ for both the high- and low-smoke cases. As already mentioned, the spread of main spray flame was slower in these cases. This realized weak interaction between the main and post spray/flame, which led to a higher smoke reduction rate when soot from the post spray was suppressed by selecting the post injection timing. A high value of $\alpha$ was also observed in the lower injection pressure case (70 $\mathrm{MPa}$ ) and advanced main injection case $\left(-1{ }^{\circ}\right.$ ATDC $)$ for the low-smoke case. Regarding the effect of the main injection timing, the larger smoke reduction at the advanced injection timing seemed to be caused by the reduced main-post injection interval (Fig. 9). The lower injection pressure would weaken the interaction between the main and post spray/flame for a smaller total injection quantity, while the interaction was not suppressed when the injection quantity was increased.

The increased post injection quantity $\left(6 \mathrm{~mm}^{3}\right)$ and higher injection pressure (125 $\mathrm{MPa}$ ) provided a markedly lower $\alpha$ in the case of low smoke. As already described, the enhanced penetration of the post spray would be the cause of the smaller smoke reduction effect in these cases. In the case of the 
Table 8. Smoke reduction rates by post injection.

\begin{tabular}{|c|c|c|c|c|c|c|c|c|c|c|c|}
\hline & \multirow{2}{*}{ Standard } & \multicolumn{2}{|c|}{$q_{\text {post }}$} & \multicolumn{2}{|c|}{$p_{\mathrm{j}}$} & $p_{\mathrm{b}}$ & \multicolumn{2}{|c|}{$\theta_{\text {main }}$} & \multirow{2}{*}{$\begin{array}{c}\text { Nozzle } \\
10 \text { holes }\end{array}$} & \multirow{2}{*}{\begin{tabular}{|c|} 
Bowl shape \\
T55
\end{tabular}} \\
\hline & & & $2 \mathrm{~mm}^{3} /$ cycle & $6 \mathrm{~mm}^{3} /$ cycle & $70 \mathrm{MPa}$ & $125 \mathrm{MPa}$ & $140 \mathrm{kPa}$ & $-1^{\circ}$ ATDC & $3^{\circ} \mathrm{ATDC}$ & & \\
\hline \multirow{4}{*}{$\begin{array}{l}\text { Low } \\
\text { smoke }\end{array}$} & $q_{\mathrm{f}}\left[\mathrm{mm}^{3} /\right.$ cycle $]$ & 29.0 & 29.0 & 29.0 & 25.0 & 31.0 & 33.0 & 27.0 & 28.5 & 28.0 & 25.0 \\
\hline & $\Delta S$ & 0.24 & 0.17 & 0.07 & 0.31 & 0.04 & 0.25 & 0.47 & 0.31 & 0.53 & 0.39 \\
\hline & $\Delta S_{0}$ & 0.42 & 0.30 & 0.70 & 0.44 & 0.59 & 0.41 & 0.56 & 0.56 & 0.61 & 0.50 \\
\hline & $\alpha$ & 0.55 & 0.57 & 0.10 & 0.71 & 0.07 & 0.61 & 0.84 & 0.55 & 0.87 & 0.78 \\
\hline \multirow{4}{*}{$\begin{array}{l}\text { High } \\
\text { smoke }\end{array}$} & $q_{\mathrm{f}}\left[\mathrm{mm}^{3} /\right.$ cycle $]$ & 33.0 & 33.0 & 33.0 & 31.0 & 34.0 & 38.0 & 32.0 & 33.0 & 32.0 & 29.0 \\
\hline & $\Delta S$ & 0.73 & 0.34 & 0.66 & 0.55 & 0.47 & 0.53 & 0.71 & 0.62 & 0.79 & 0.87 \\
\hline & $\Delta S_{0}$ & 1.15 & 0.82 & 1.44 & 0.90 & 1.51 & 0.93 & 1.14 & 1.06 & 1.09 & 1.03 \\
\hline & $\alpha$ & 0.63 & 0.42 & 0.46 & 0.61 & 0.31 & 0.56 & 0.62 & 0.58 & 0.73 & 0.85 \\
\hline
\end{tabular}

increased post injection quantity, the post spray would strengthen the interaction with the main spray flame. In addition, it would be an additional source of smoke emission, especially in the case of lower soot from the main spray flame. On the other hand, for the higher injection pressure, the intensive interaction would be a major reason for the lower $\alpha$.

Thus, an overall explanation seems to be possible considering the interaction between the main and post spray/flames.

\section{Conclusions}

An experimental study was carried out with pilot-main-post three-stage injection using a single-cylinder diesel engine and changing the post injection timing using different settings for various parameters: the post-injection quantity, injection pressure, boost pressure, main-injection timing, number of injection nozzle orifices, and combustion chamber shape. Experiments were performed under a fixed NOx emission condition by selecting total injection quantities that made it possible to obtain predetermined smoke emission levels for the pilot-main two-stage injection mode. The smoke reduction effects of post injection were compared when changing the above parameters. The following conclusions are derived:

- When using the standard combination of combustion chamber and injection nozzle (reentrant and 7-hole nozzle), advancing the post injection reduced the smoke emission below the smoke level without post injection under the condition of a fixed total injection quantity. This smoke emission trend against the post injection timing was not qualitatively influenced by varying the post injection quantity, injection pressure, boost pressure, or main injection timing.

- The sensitivity of the smoke emission to the post injection timing decreased for a nozzle with an increased number of nozzle orifices (10-hole nozzle) and a toroidal combustion chamber. The smoke reduction effect of post injection was obtained even at a late post injection timing.

- The smoke reduction rate, which was defined as the decrease in smoke emission from employing post injection relative to the decrease by reducing the main injection quantity, fell to within 0-1 when the post injection timing was selected to obtain the minimum smoke emission in each parameter test. This meant that the

Page 10 of 11 smoke reduction effect was always obtained by selecting the proper post injection timing for the range of parameters in this study. The smoke reduction rate depended on the parameter and the reference level of the smoke emission.

In this study, qualitative explanations that considered the interaction of the main spray flames and post sprays were given for the smoke emission trend when the various parameters were changed. Further study is required to provide more detailed and quantitative explanations. Swirl flow is a factor in controlling the interaction between the main spray flame and post spray, as previously reported [14]. In addition, the thermal effect of the post spray flame would be important. To improve the explanation of the soot reduction mechanism by post injection, further experiments and computational fluid dynamics simulations will be performed in future work.

\section{References}

1. Han, Z., Uludogan, A., Hampson, G., and Reitz, R., "Mechanism of Soot and NOx Emission Reduction Using Multiple-injection in a Diesel Engine," SAE Technical Paper 960633, 1996, doi:10.4271/960633.

2. Chen, S., "Simultaneous Reduction of NOx and Particulate Emissions by Using Multiple Injections in a Small Diesel Engine," SAE Technical Paper 2000-01-3084, 2000, doi:10.4271/2000-01-3084.

3. Badami, M., Mallamo, F., Millo, F., and Rossi, E., "Influence of Multiple Injection Strategies on Emissions, Combustion Noise and BSFC of a DI Common Rail Diesel Engine," SAE Technical Paper 2002-01-0503, 2002, doi:10.4271/2002-01-0503.

4. Park, C., Kook, S., and Bae, C., "Effects of Multiple Injections in a HSDI Diesel Engine Equipped with Common Rail Injection System," SAE Technical Paper 2004-01-0127, 2004, doi:10.4271/2004-01-0127.

5. Hotta, Y., Inayoshi, M., Nakakita, K., Fujiwara, K. et al., "Achieving Lower Exhaust Emissions and Better Performance in an HSDI Diesel Engine with Multiple Injection," SAE Technical Paper 2005-01-0928, 2005, doi:10.4271/2005-01-0928.

6. Dronniou, N., Lejeune, M., Balloul, I., and Higelin, P., "Combination of High EGR Rates and Multiple Injection Strategies to Reduce Pollutant Emissions," SAE Technical Paper 2005-01-3726, 2005, doi:10.4271/2005-01-3726. 
7. Desantes, J., Arrègle, J., López, J., and García, A., "A Comprehensive Study of Diesel Combustion and Emissions with Post-injection," SAE Technical Paper 2007-01-0915, 2007, doi:10.4271/2007-01-0915.

8. Arrègle, J., Pastor, J.V., López, J.J., García, A., "Insights on Post Injection-Associated Soot Emissions in Direct Injection Diesel Engines," Combustion and Flame 154(3):448-461, 2008.

9. Ogawa, H., Yoshida, T., Takahashi, K., and Numata, A., "Improvements in Diesel Combustion with After-Injection," SAE Technical Paper 2008-01-2476, 2008, doi:10.4271/2008-01-2476.

10. Ikemoto, M., Omae, K., and Nishida, K., "In-Cylinder Experimental Analysis Using Piezo-Driven Diesel Injector Equipped With Needle-Lift Sensor," JSAE Trans., 41(6):1347-1352, 2010. (in Japanese)

11. Bobba, M., Musculus, M., and Neel, W., "Effect of Post Injections on In-Cylinder and Exhaust Soot for LowTemperature Combustion in a Heavy-Duty Diesel Engine," SAE Int. J. Engines 3(1):496-516, 2010, doi:10.4271/2010-01-0612.

12. Long, L., Horibe, N., Komizo, T., Tamura, I., and Ishiyama, T., "An Experimental Study on Smoke Reduction Effect of Post Injection Combination With Pilot Injection for a Diesel Engine," J. Eng. Gas Turbines Power 136(4):041502-1041502-8, 2014, doi:10.1115/1.4025929.

13. Beatrice, C., Belardini, P., Bertoli, C., Lisbona, M.G., and Rossi Sebastiano, G.M., "Diesel Combustion control in common rail engines by new injection strategies," Int. J. Eng. Research 3(1):23-36, 2002, doi: $10.1243 / 1468087021545513$

14. O'Connor, J. and Musculus, M., "Post Injections for Soot Reduction in Diesel Engines: A Review of Current Understanding," SAE Int. J. Engines 6(1):2013, doi:10.4271/2013-01-0917

\section{Contact Information}

Naoto HORIBE

Phone and Fax: $\quad+81-75-753-5269$

Email: horibe@energy.kyoto-u.ac.jp

\section{Acknowledgments}

Honda Motor Co., Ltd is acknowledged for providing the engine system. The authors would like to thank Mr. Masato YAGI for his valuable assistance with the experiments.

\section{Definitions/Abbreviations}

$\mathrm{d} Q / \mathrm{d} \theta \quad$ Rate of heat release

$q$

Total injection quantity

$q_{\text {main }}$

Main injection quantity

$q_{\text {pilot }}$

Pilot injection quantity

$q_{\text {post }}$

Post injection quantity

$\theta_{\text {main }}$

Main injection timing

$\theta_{\text {pilot }}$

Pilot injection timing

$\theta_{\text {post }}$

Post injection timing

$p_{\mathrm{b}}$

Boost pressure

$p_{\mathrm{j}}$

Injection pressure

$\Delta S$

Smoke-emission difference between the case of two-stage injection (pilot + main) and the case with post-injection (pilot + main + post)

$\Delta \mathbf{S}_{0}$

Smoke-emission difference between the two cases of two-stage injection (pilot + main) and (pilot + reduced main)

Smoke reduction rate

DPF

Diesel particulate filter

ECU

Electronic control unit

EGR

Exhaust gas recirculation

FSN

Filter smoke number

IMEP

Indicated mean effective pressure

JIS

Japanese industrial standards

TDC 